Investigations of STaR Clusters,-Further results of an extensive investigation of the magnitudes and colours of stars in clusters, which is in progress at Mt. Wilson, have been given by Dr. Harlow Shapley (Contributions from the Mt. Wilson Solar Observatory, Nos. II5, II6, and II7). The problems presented by clusters are stated in the first paper, while the second and third deal respectively with the globular cluster in Hercules, and the open cluster $\mathrm{M}_{37}$.

In the case of the Hercules cluster, a catalogue of I 300 stars has been prepared, involving more than ro,000 estimates and measurements of magnitude. The colour-indices suggest that there is no appreciable selective scattering of light in space in the direction of the Hercules cluster, but the apparent increase of redness towards the centre would seem to imply an absorption within the cluster itself. There is an almost linear decrease of colour-index with decreasing brightness in all regions of the cluster, and this feature will probably have great significance in regard to the evolution of giant stars. A conclusion of special interest is that the parallax of the Hercules cluster must be less than $0.0001^{\prime \prime}$, and is probably greater than $0.00001^{\prime \prime}$. At the provisionally adopted distance of roo, ooo light years, the cluster would be more than rooo light years in diameter. As viewed from the cluster, our sun would appear fainter than the 22nd magnitude, and our entire galactic system would have an angular diameter of about $5^{\circ}$, perhaps comparing closely in general appearance with the Greater Magellanic Cloud as seen from the earth. It is probable that no star so faint as the sun has yet been photographed in this cluster, and that a large number are more than 200 times the solar brightness. Dr. Shapley considers it reasonably clear that the Hercules and other similar clusters are very distant systems, distinct from our galaxy, and perhaps not greatly unlike it in size and form. The open clusters, on the other hand, seem to be relatively small parts of the local system.

It is interesting to note further that five new variables have been discovered in the Hercules cluster, making a total of seven now known. It is probable that all of them are of the Cepheid type.

The Almanac of the Madrid Observatory.-The issue of this publication for I 917 contains the customary astronomical information; ephemerides, and tables, with the necessary explanatory matter. In addition, there is a useful article on the speotroscopic classification of stars, by Prof. Iniguez, with photographic illustrations, and a very full account of the methods of determining latitude. Details of the meteorological observations and of the observations of sun-spots, faculæ, and solar prominences made at the Madrid Observatory occupy nearly 300 pages of the volume.

\section{SOUND-AREAS OF GREAT EXPLOSIONS.}

$\mathrm{IT}$ is not often that a great explosion occurs near the centre of a populous area, and the recent disaster in East London thus offers an opportunity of adding to our knowledge on the transmission of soundwaves by the atmosphere. A brief summary may first be given here of the results obtained in recent investigations. The most remarkable result is the recognition of the fact that there exists sometimes, not always, a zone of silence which separates two detached sound-areas. This zone has been traced in twenty recent explosions (excluding that of Friday, January 19), two being due to gun-firing, four to explosions of dynamite or gunpowder, and the remainder to volcanic explosions in Japan.

The source of sound is always unsymmetrically placed within the inner sound-area, and nearly always NO. 2466 , VOL. 98] lies on the side facing the outer sound-area. On this side the boundary of the inner area may be as near as $2 \frac{1}{2}$ miles, or as distant as thinty-nine miles, from the source. The most important dimension, however; is the radius, or mean radius, of the curve which forms the outer boundary of the zone of silence. It is far from being constant. It may be- as low as fifty miles, as with the minute-guns fired at Spithead on February I, IgoI, or as high as ninety-nine miles, as with the Wiener-Neustadt explosion of r9I2.

During the four years I909-I3 eleven explosions of the volcano Asamayama, in central Japan, have given rise to double sound-areas, in most of which the outer area is the larger. The inner area is arranged with a rough approach to symmetry about the ash-precipitation zone. This is usually a long niarrow band, the direction of which is determined by that of the higher air-currents into which the smokecloud from the volcano rises. The direction of the band is usually towards the east, but varies between north-east and south-east, and it is a significant fact that, as Prof. Omori has pointed out, the centre of the outer sound-area is usually on or close to the continuation westwards of the ash-precipitation zone. Of twenty-two important explosions of the Asamayama from December, I909, to the end of 19r3, Prof. Omori notices that single sound-areas occur just as frequently as double sound-areas. Nine of the former occurred in the six winter months, and ten of the latter in the six summer months. On the theory that the zone of silence is due to the refraction of the sound-rays by winds varying in velocity, and sometimes also in direction, with the altitude, $\mathrm{Mr}$. S. Fujiwhara has shown that, with the normal type of winter weather in Japan, the sound-areas would be single, and with that of summer weather, double.

With regard to the distance to which explosions may be heard, it would be well to separate those in which the sound-areas were single from those in which they were double. Of the first class, the explosion at Avigliana (notthern Italy) in 1900 was heard at Lugano, ninety-nine miles distant. The explosion in the same year at Kobe (southern Japan), which probably belongs to this class, was heard at ninety-seven miles. Of explosions with double sound-areas, the distances are ninety miles for the Hayle (Cornwall) explosion of I904, about II 2 miles for the Förde (Westphalia) explosion of 1903 and the Jungfrau railway explosion of I908, and I86 miles for the great explosion at Wiener Neustadt in I9I2.

Though later accounts may modify some of the dimensions given below, a first analysis of the reports already received shows that the explosion in East London on January ig belongs to the class with double sound-areas. The inner area is of unusual form, being L-shaped, with the angle near Godalming, the east-and-west limb reaching to Canterbury, and the north-and-south limb to the neighbourhood of Northampton. The least distance of the boundary of the inner area from the source of sound is about twelve miles, and the greatest distance sixty-five miles.

The outer sound-area lies to the north of the other, with its centre a few miles west of King's Lynn. Its longer axis ( $3_{3} \mathrm{I}$ miles in length) reaches from the neighbourhood of Nottingham to that of Lowestoft, its width being about fifty-five miles. The zone of silence viaries in width from sixteen miles (near Northampton) to fifty-four miles, and the distance of its outer boundary from the source is about sixty miles. So far as is known at present, it includes the greater part of Essex and Suffolk, the southern half of the counties of Cambridge and Huntingdon, and the central portion of Northamptonshire. Even if observations should be received afterwards from this area, it is significant that, from the inner sound-area of about 
3500 square miles, I have so far received 250 records in which the time is given, from the outer sound-area of about 5700 square miles 223 records (including 122 from Norfolk and fifty-six from Lincolnshire), and from the zone of silence of about 4500 square miles only one, and that one close to the sea. The greatest distance to which the sound-waves penetrated is about I2 I miles.

A remarkable feature about these records is that, though all of them have been sent in reply to my newspaper letters (and therefore sent as it were at random), they are almost as thickly grouped near the boundaries as near the centres of the two areas. There is none of that increasing sparseness of records near the boundary which is so characteristic of earthquake investigations. It would seem as if the boundary were determined, not by the sound-vibrations becoming inaudible, but by the absence of soundvibrations from the area beyond. It may be of interest to add that, at a large number of places, pheasants showed signs of alarm, as they did during the North Sea battle of January 24, I915.

May I, in conclusion, state how glad I should be to receive (address: 16 Manor Road, Edgbaston, Birningham) further acoounts of the explosion, and especially negative records? Observations on the direction of the surface and upper winds would be of great value. Charles Davison.

\section{RECENT PAPERS ON PARASITES.}

$\mathrm{O}$

$\mathrm{NE}$ of the most notorious of protozoan parasites at the present time is the microsporidian Nosema apis, which, since the well-known researches of Drs. H. B. Fantham and Annie Porter in 1912, has been generally regarded as the cause of "Isle of Wight disease " in hive-bees. In the Proceedings of the Royal Physical Society of Edinburgh (vol. xx., part r) two papers have lately appeared in which this conclusion is called in question-one by John Anderson, the other by the same author in collaboration with Dr. John Rennie. Stress is laid on the possibility of bees heavily infested with Nosema showing no symptoms of the disease; this condition was recognised by Fantham and Porter, who attributed it to immunity in certain strains, and directed attention to the danger caused to other bees by such "carriers." On the other hand, an epidemic of disease among bees on Deeside with all the characteristic "Isle of Wight" symptoms appeared to be unaccompanied by any trace of Nosema in the affected insects. It may, of course, be retorted that the parasites were present in inconspicuous stages and in relatively small numbers, as Fantham and Porter concluded to be the case in similar instances observed by them. Anderson and Rennie, however, "are unable to recognise any causal relation between the presence of this parasite and the disease," though it "may be a contributing weakening factor favouring in certain cases the development of the disease." It may be doubted if the authors sufficiently recognise the possibly deadly effects, on certain strains of bees; of parasites so few in number as to escape observation.

Students of the Sporozoa will read with more than usual interest Dr. Howard Crawley's paper entitled "The Sexual Evolution of Sarcocystis muris" (Proc. Acad. Nat. Sci., Philadelphia, lxviii., part I), in which the early development of the parasites in the intestinal cells of the mouse is described with numerous figures. The spores swallowed by the mouse reach the hinder-end of the small intestine within an hour and invade the epithelial cells. Some spores then undergo a great enlargement of the nucleus and degeneration of the cytoplasm, while others remain much as when they entered the cell, becoming, however, relatively. shorter and broader than the original spores; the author regards the former as male and the latter as female gametes. From six to fifteen hours after penetration chromatin granules separate from the nucleus and are absorbed by the protoplasm; this process is interpreted as maturation. "Finally, in the eighteen-hour stage, macrogametes may be found which in some cases show minute, thread-like bodies upon their surfaces, and in others contain within their substances small, solid chromatic bodies, one in each case. These appearances are regarded as warranting the interpretation that fertilisation takes place." Dr. Crawley's work goes far to establish the existence of a sexual phase in the sarcosporidian life-cycle, but it appears to fall short of demonstration.

In the Proceedings of the U.S. National Museum (vol. 1., No. 2131) an important systematic paper on "Nematode Parasites of the Rodentia and Hyracoidea" has been published by Maurice C. Hall. Most of the species described are illustrated by clear structural figures, and there are diagnoses of the various classificatory groups, so that the paper will be of much value to students. In the class-diagnosis of the Nematoda it is rather surprising to find no stress laid on the entirely epithelial nature of the intestinal wall or on the anomalous character of the body-cavity.

Several papers on parasites are to be found in the lately issued third and fourth reports of the director of veterinary research for the South African Union Department of Agriculture (Pretoria, I9I6). Sir A. Theiler and W. Robertson describe the life-history of Trichostrongylus douglasi, a nematode parasite of the ostrich, somewhat unfortunately called a "wireworm." The four larval stages are carefully distinguished, and it is shown that the young worm can survive and become mature in the bird's stomach only when swallowed in its late second stage. No evidence that the worms ever enter through the skin could be obtained. Dr. F. Veglia contributes an exhaustive paper on "The Anatomy and Life-history of Haemonchus contortus," a well-known strongylid parasite of the stomach in ruminants; in this memoir a number of structural and bionomic details are recorded. The photographs and careful drawings illustrating these reports are reproduced in excellent style; it is all the more disappointing to find that for the letterpress of these valuable zoological papers a cheap contract method has apparently been adopted by the South African Government which recalls the worst traditions of our Home Stationery Office.

\section{THE LOUTREUIL FUND.}

\section{GRANTS FOR SCIENTIFIC WORK.}

IN the Comptes rendus of the Paris Academy of Sciences for November 27 is given the report of the council of the Loutreuil Foundation. The grants allotted are divided into three groups, as follows :-

I. Establishments Mentioned by the Testator.(I) Museum of Natural History. 2000 francs to Prof. Louis Roule for the continuation of his researches on the migratory fishes of French marine and fresh waters, the Salmonideæ in particular. ro,ooo francs for refitting the maritime laboratory of the Island of Tatihou at Saint-Vaast-La-Hougue. This laboratory has been used as a concentration camp since the outbreak of war, and considerable damage has been done. (2) The Collège de France. 700 francs to E. Gley to complete the frigorific installation for which an allocation was made last year. $435^{\circ}$ francs to Prof. Nageotte for the purchase of apparatus for pursuing his studies on the regeneration of nerves. 4000 francs to M. l'Abbé Rousselot for continuing and developing the experiments commenced by him on locating artillery by No. 2466, VOL. 98] 